Astrida Budiarti. Penyebab Keberhasilan Dan Kegagalan Pemberian Asi Eksklusif Di Puskesmas Jagir Surabaya

\title{
PENYEBAB KEBERHASILAN DAN KEGAGALAN PEMBERIAN ASI EKSKLUSIF DI PUSKESMAS JAGIR SURABAYA
}

\author{
Astrida Budiarti \\ Stikes Hang Tuah Surabaya \\ Email : as3da ns@yahoo.com
}

\section{ABSTRAK}

Pemberian makanan terbaik bagi bayi adalah dengan menyusui bayi secara eksklusif sejak lahir sampai umur 6 bulan. Namun kenyataannya, pemberian ASI belum sesuai dengan target. Tujuan penelitian ini untuk menganalisis penyebab keberhasilan dan kegagalan ASI ekslusif di Puskesmas Jagir Surabaya.

Metode penelitian adalah observasional analitik dengan pendekatan Cross Sectional. Populasi ibu yang mempunyai anak usia 6-12 bulan di Puskesmas Jagir sebanyak 50 orang. Teknik pengambilan sampel dengan purposive sampling dengan sampel sebanyak 42 responden. Instrument penelitian dengan kuesioner untuk mengumpulkan data pemberian ASI eksklusif. Data analisa dengan uji Chi-Square.

Hasil penelitian menunjukkan ada hubungan antara edukasi ASI selama ANC terhadap keberhasilan dan kegagalan pemberian ASI eksklusif dengan nilai $\rho=0.030$,. Terdapat hubungan antara pengalaman Ibu terhadap keberhasilan dan kegagalan pemberian ASI eksklusif dengan nilai $\rho=0.001$ dimana. Terdapat hubungan antara IMD terhadap keberhasilan dan kegagalan pemberian ASI eksklusif dengan nilai $\rho=0.001$.

Edukasi, pengalaman ibu, dan IMD sangat berpengaruh terhadap pemberian ASI ekslusif, oleh karena itu penting bagi tenaga medis untuk memberikan edukasi berupa penyuluhan dan sosialisasi untuk meningkatkan kesadaran ibu tentang pentingnya pemberian ASI ekslusif.

Kata Kunci: Edukasi, Pengalaman ibu, IMD, ASI Ekslusif

\section{ABSTRACT}

Giving the best food for babies is by giving exclusive babies from birth until the age of 6 months. However, ASI assistance has not met the target. Exclusive ASI at Jagir Surabaya Health Center.

Observational analytic research methods using cross sectional. The population of mothers who have children aged 6-12 months in Puskesmas Jagir is 50 people. The sampling technique was purposive sampling with a sample of 42 respondents. Research instrument with a questionnaire to collect data on exclusive breastfeeding. Data analysis with Chi-Square test.

The results showed there was a relationship between breastfeeding education during ANC on the success and failure of exclusive breastfeeding with a value $\square=0.030$. There is $a$ relationship between your experience with the success and failure of exclusive breastfeeding with a value $\square=0.001$ where. There is a relationship between IMD and the success and failure of exclusive breastfeeding with a value $\square=0.001$.

Education, mother's experience, and IMD are very influential on exclusive breastfeeding, therefore it is important for medical staff to provide education in the form of counseling and outreach to increase maternal awareness about the importance of exclusive breastfeeding.

Keywords: Education, mother's experience, IMD, exclusive breastfeeding

Keywords: Education, Mother's Experience, IMD, Exclusive Breastfeeding 


\section{PENDAHULUAN}

ASI eksklusif didefinisikan sebagai pemberian ASI sedini mungkin setelah persalinan, diberikan tanpa jadwal dan tidak ada makanan tambahan sampai dengan bayi berumur enam bulan. Makanan tambahan yang di maksud yaitu susu formula, air matang, jus buah, air gula, dan madu. Vitamin, mineral, maupun obat dalam bentuk sirup atau tetes tidak termasuk dalam makanan tambahan (Pearl et all, 2004 dalam Dee, 2007). Cara pemberian makanan pada bayi yang baik dan benar adalah menyusui bayi secara eksklusif sejak lahir sampai umur 6 bulan dan meneruskan sampai anak usia 24 bulan (Kemenkes RI, 2013). Namun Kenyataannya di lapangan, khususnya di Indonesia, pemberian ASI eksklusif kepada bayi sejak lahir sampai berusia 6 bulan masih belum sesuai target yang diharapkan. Rendahnya angka balita yang disusui dipengaruhi oleh berbagai faktor, baik dari faktor ibu, keluarga maupun peran serta dari tenaga kesehatan. Faktor yang bisa mempengaruhi antara lain faktor edukasi selama ANC, pengalaman ibu, pelaksanaan IMD, dan dukungan tenaga kesehatan.

Pemberian ASI eksklusif di Indonesia, memiliki manfaat yang besar terhadap penurunan resiko morbiditas dan mortalitas pada bayi. Namun pemberian ASI eksklusif masih tergolong rendah. Penelitian dan pengamatan yang dilakukan menunjukan dengan jelas adanya kecenderungan semakin meningkatnya jumlah ibu yang tidak menuyusui bayinya. Prevalensi bayi yang diberi ASI eksklusif usia 0-12 bulan di indonesia sebanyak $44,7 \%$ dan di jawa timur sebanyak 48,1\%. Hasil Riset Kesehatan Dasar 2013 menunjukkan bahwa persentase pemberian ASI saja dalam 24 jam terakhir semakin menurun seiring meningkatnya umur bayi dengan persentase terendah pada anak umur 6 bulan $(30,2 \%)$, (RisKesDas, 2013). Berdasarkan studi pendahuluan terhadap 24 ibu di Puskesmas Jagir Surabaya, 4 orang (20\%) memberikan ASI eksklusif, 18 ibu (18\%) memberikan ASI dengan susu formula dan makanan pendamping, dan (2\%) ibu yang tidak memberikan ASI sama sekali.

Pemberian ASI eksklusif memberikan manfaat yang bagus bagi bayi dan keluarga, dimana ASI akan meningkatkan IQ, meningkatkan daya tahan tubuh, mengurangi resiko alergi, serta ekonomis bagi keluarga karena tidak perlu membeli susu formula. ASI juga selalu bisa siap kapan saja. Kejadian kekurangan gizi, pembentukan imun tidak sempurna, salah satu faktor adalah karena buruknya pemberian ASI (Depkes, 2007). Pengetahuan tentang manfaat ASI eksklusif juga berperan serta dalam keberhasilan pemberian ASI Eksklusif. Komunikasi tentang Pemberian ASI eksklusif dari pihak puskesmas ke masyarakat khususnya ibu yang menyusui sudah gencar dilakukan melalui penyuluhan (pendidikan kesehatan tentang ASI) diposyandu.

\section{METODE PENELITIAN}

Metode yang digunakan adalah observasional analitik dengan pendekatan Cross Sectional. Pelaksanaan bulan MeiJuli 2018 di Puskesmas Jagir Surabaya. Populasi ibu yang mempunyai anak 6-12 bulan di Puskesmas Jagir sebanyak 50 orang. Teknik sampling dengan purposive sampling. Sampel sebanyak 42 orang ibu yang mempunyai anak usia 6-12 bulan yang berada Puskesmas Jagir. Instrument penelitian dengan kuesioner

\section{HASIL PENELITIAN}

1. Hubungan Edukasi ASI Selama ANC dengan Keberhasilan dan Kegagalan ASI Eksklusif

\begin{tabular}{|c|c|c|c|c|c|c|}
\hline \multirow{3}{*}{$\begin{array}{c}\text { Edukasi } \\
\text { selama } \\
\text { ANC }\end{array}$} & \multicolumn{4}{|c|}{$\begin{array}{c}\text { Pemberian ASI } \\
\text { eksklusif }\end{array}$} & \multicolumn{2}{|c|}{ Total } \\
\hline & & $\mathrm{Ya}$ & & dak & & \\
\hline & $f$ & (\%) & $f$ & (\%) & $\mathrm{N}$ & $\%$ \\
\hline $\mathrm{Ya}$ & 9 & 50 & 9 & 50 & 18 & 100 \\
\hline Tidak & 1 & 4,2 & $\begin{array}{l}2 \\
3\end{array}$ & $\begin{array}{c}95 \\
8\end{array}$ & 24 & 100 \\
\hline
\end{tabular}


Astrida Budiarti. Penyebab Keberhasilan Dan Kegagalan Pemberian Asi Eksklusif Di Puskesmas Jagir Surabaya

\begin{tabular}{lllll}
\hline \multirow{2}{*}{ Total } & 1 & 3 & 42 & 100 \\
& 0 & 2 & & \\
\hline
\end{tabular}

Nilai uji statistik Chi-Square 0,03 (

Hubungan edukasi ASI selama ANC dengan pemberian ASI ekslusif di Puskesmas Jagir Surabaya didapatkan data bahwa dari 42 responden yang mendapatkan edukasi ASI selama ANC dan memberikan ASI ekslusif sebanyak 9 orang (50\%), yang mendapatkan edukasi ASI selama ANC dan tidak memberikan ASI ekslusif sebanyak 9 orang $(50 \%)$, sementara responden yang tidak mendapatkan edukasi ASI selama ANC dan memberikan ASI ekslusif sebanyak 1 orang $(4,2 \%)$, dan yang tidak mendapatkan edukasi ASI selama ANC dan tidak memberikan ASI ekslusif sebanyak 23 orang $(95,8 \%)$. Hasil uji statistik Chi-Square didapatkan hasil $\rho=0.030$ dimana $\rho<0,05$ maka dapat disimpulkan bahwa edukasi ASI selama ANC berpengaruh terhadap keberhasilan ASI eksklusif di Puskesmas Jagir Surabaya.

2. Hubungan Pengalaman lbu dengan Keberhasilan dan Kegagalan ASI Eksklusif

\begin{tabular}{ccc|cccc}
\hline \multirow{2}{*}{$\begin{array}{c}\text { Pengala } \\
\text { man Ibu }\end{array}$} & \multicolumn{4}{c}{ Pemberian ASI } & \multicolumn{2}{c}{ Total } \\
\cline { 2 - 7 } & \multicolumn{2}{c}{ Ya } & \multicolumn{2}{c}{ Tidak } \\
& $\mathrm{f}$ & $(\%)$ & $\mathrm{f}$ & $(\%)$ & $\mathrm{N}$ & $\%$ \\
\hline Ya & 9 & 50 & 9 & 50 & 18 & 100 \\
Tidak & 1 & 4,2 & 23 & 95,8 & 24 & 100 \\
\hline Total & 10 & \multicolumn{3}{c}{32} & \multicolumn{3}{c}{42} & 100 \\
\hline Nilai uji statistik Chi-Square & $\mathbf{0 , 0 0}$ \\
\hline
\end{tabular}

Data menunjukkan dari 42 responden yang mempunyai pengalaman dan melakukan pemberian ASI sebanyak 9 orang $(50 \%)$, yang mempunyai pengalaman dan tidak melakukan pemberian ASI sebanyak 9 orang $(50 \%)$, sementara responden yang tidak mempunyai pengalaman dan melakukan pemberian ASI sebanyak 1 orang $(4,2 \%)$, dan responden yang tidak mempunyai pengalaman dan tidak melakukan pemberian ASI sebanyak 23 orang $(95,8 \%)$. Hasil uji statistik ChiSquare didapatkan hasil $\rho=0.000$ dimana $\rho<$ 0,05 , disimpulkan bahwa pengalaman lbu berhubungan dengan keberhasilan dan kegagalan pemberian ASI eksklusif di Puskesmas Jagir Surabaya.

3. Hubungan IMD dengan Pemberian ASI

\begin{tabular}{|c|c|c|c|c|c|c|}
\hline \multirow{3}{*}{ IMD } & \multicolumn{4}{|c|}{ Pemberian ASI } & \multirow{2}{*}{\multicolumn{2}{|c|}{ Total }} \\
\hline & \multicolumn{2}{|c|}{$\mathrm{Ya}$} & \multicolumn{2}{|c|}{ Tidak } & & \\
\hline & (f) & (\%) & (f) & (\%) & $\mathrm{N}$ & $\%$ \\
\hline $\mathrm{Ya}$ & 9 & 50 & 9 & 50 & 18 & 100 \\
\hline Tidak & 1 & 4,2 & 23 & 95,8 & 24 & 100 \\
\hline Total & 10 & & 32 & & 42 & 100 \\
\hline \multicolumn{7}{|c|}{ 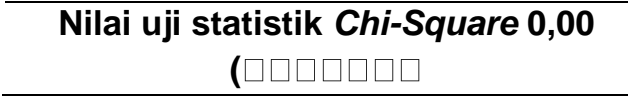 } \\
\hline
\end{tabular}

Hubungan IMD dengan pemberian ASI di Puskesmas Jagir Surabaya didapatkan data bahwadari 42 responden yang melakukan IMD dan melakukanpemberian ASI sebanyak 9 orang $(50 \%)$, yang melakukan IMD dan tidak melakukan pemberian ASI sebanyak 9 orang $(50 \%)$, sementara responden yang tidak melakukan IMD dan melakukan pemberian ASI sebanyak 1 orang $(4,2 \%)$, dan responden yang tidak melakukan IMD dan tidak melakukan pemberian ASI sebanyak 23 orang (95,8\%). Hasil uji statistik Chi-Square didapatkan hasil $\rho=0.000$ dimana $\rho<0,05$ makadapat disimpulkan bahwa terdapat hubungan antara IMD dengan pemberian ASI di Puskesmas Jagir Surabaya.

\section{PEMBAHASAN}

1. Hubungan Edukasi ASI selama ANC dengan pemberian ASI eksklusif

Hasil penelitian menunjukkan ada hubungan edukasi ASI terhadap pemberian ASI eksklusif. Artinya terdapat hubungan edukasi ASI selama ANC dengan pemberian ASI eksklusif. 
Memberikan ASI secara eksklusif adalah intervensi yang efektif untuk menurunkan mortalitas neonatus, selain vaksinasi tetanus toksoid.

Memperhatikan faktor-faktor karakteristik responden, maka upaya edukasi untuk promosi ASI eksklusif harus menjangkau seluruh masyarakat, namun perlu lebih ditekankan di daerah perkotaan dengan pertimbangan di perkotaan cenderung lebih banyak yang tidak memberikan ASI eksklusif. Sehingga untuk melawan gencamya promosi susu formula, maka informasi tentang keuntungan ASI perlu lebih ditingkatkan. Rendahnya cakupan pemberian ASI eksklusif disebabkan karena masih kurangnya informasi terkait manfaat pemberian ASI serta dukungan sosial dari lingkungan terhadap pelaksanaan menyusui selain kondisi demografis dan ekonomis.

Sebagian responden (53,6\%) mengaku telah memperoleh informasi tentang ASIIMP-ASI selama kehamilannya. Informasi tersebut sebagian besar diterima dari tenaga kesehatan. Namun, terdapat juga responden yang mendapatkan informasi tentang ASIIMP-ASI di rumah orang tua, saudara dan tetangga (nonyankes). Penelitian Widodo, Y, dkk. Menyatakan pemberian konseling berdampak semakin tingginya cakupan ASI eksklusif. Mempertimbangkan hal ini, petugas kesehatan diharapkan lebih meningkatkan kualitas dan kuantitas pelayanan konseling kepada ibu hamil.

Oleh karena itu upaya edukasi untuk promosi ASI eksklusif dan pemberian MP-ASI masih perlu ditingkatkan lagi baik memalui media massa maupun melalui petugas kesehatan setempat yang dikemas dengan baik dan dilengkapi dengan media edukasi yang lebih menarik.

2. Hubungan Pengalaman lbu dengan Pemberian ASI
Hasil penelitian menunjukkan terdapat hubungan pengalaman ibu dengan pemberian ASI. Pengalaman yang diperoleh dan faktor lingkungan bisa mempengaruhi pengetahuan ibu dan akhirnya terbentuk respon yaitu perilaku memberikan ASI. Pengalaman merupakan salah satu sumber pengetahuan untuk masa sekarang. Pengalaman sebelumnya dalam menyusui dapat berpengaruh dalam mengambil keputusan untuk memberikan ASI (Arisman, 2010).

Hasil penelitian hubungan pengalaman menyusui dan pemberian ASI eksklusif menunjukan bahwa terdapat hubungan antara pengalaman menyusui dengan pemberian ASI eksklusif. Pengalaman menyusui anak sebelumnya berhubungan positif dengan pemberian ASI, terutama anak yang sebelumnya dengan pemberian ASI pada anak saat ini. Pengalaman menyusui perempuan primipara berperan penting pada pemberian ASI anak selanjutnya (Phillips, 2011). Selain itu pengalaman menyusui tidak hanya dari pengalaman menyusui sebelumnya. Namun, juga dipengaruhi oleh budaya keluarga. Jika pengalaman orang tuanya dulu tidak melakukan ASI eksklusif, bisa berdampak menurunkan tekanan kepada anaknya untuk memberikan ASI eksklusif. Selain itu faktor struktur keluarga juga berpengaruh. Bentuk keluarga besar, bisa mendorong sikap pemberian ASI eksklusif, terutama saat inisiasi (Agunbiade, 2012).

3. Hubungan IMD dengan Pemberian ASI Hasil penelitian menunjukkan ada hubungan pemberian IMD dengan pemberian ASI. IMD atau kemampuan untuk melakukan immediate breastfeeding merupakan salah satu faktor keberhasilan ASI eksklusif. Petugas kesehatan yang memfasilitasi ibu untuk IMD ketika persalinan, diharapkan interaksi ibu dan bayi akan 
cepat terwujud. Manfaat pelaksanaan IMD yaitu membuat ibu percaya diri dalam memberikan ASI, sehingga bayi menjadi nyaman berada pada payudara ibu (Fikawati dan Syafiq, 2009).

Menurut hasil penelitian Agudelo et al (2016) inisiasi menyusu dini dianjurkan pada bayi, agar bayi belajar menghisap puting susu serta mempersiapkan ibu mulai memproduksi ASI, bukan untuk pemberian nutrisi. Bayi yang dilakukan IMD selama 60 menit, menunjukkan dua kali lebih lama menyusu (Saputra dan Lasmini, 2015).

Dua jam pertama kehidupan bayi merupakan saat yang optimal bagi bayi untuk belajar menyusui. Kontak kulit bayi dengan kulit ibu pada periode ini meningkatkan kesempatan bayi untuk menyusu di 30 menit kehidupan dan jangka panjang berikutnya (Agudelo et al, 2016). Penelitian ini sejalan sejalan dengan hasil penelitian Ida (2011) yang menunjukkan terdapat hubungan bermakna antara IMD dengan keberhasilan ASI eksklusif di Wilayah Kerja Puskesmas Kemiri Muka Kota Depok.

\section{KESIMPULAN}

1. Terdapat hubungan Edukasi selama ANC dengan pemberian ASI eksklusif

2. Terdapat hubungan pengalaman ibu dengan pemberian ASI

3. Tersapat hubungan IMD dengan pemberian ASI

\section{SARAN}

1. Bagi Responden

Hasil penelitian ini sebagai dasar bagi responden agar meningkatkan kesadaran dalam memberikan ASI eksklusif pada balitanya.

2. Bagi Profesi Keperawatan

Sebaiknya bagi praktisi keperawatan agar ikut serta memberikan penyuluhan dan sosialisasi tentang manfaat ASI eksklusif

3. Bagi Puskesmas

Sebagai bahan untuk memberikan edukasi dan motivasi bagi warga di lingkup kerja puskesmas agar memberikan ASI eksklusif kepada harganya.

4. Bagi Peneliti Selanjutnya

Penelitian selanjutnya bisa mengambil judul hubungan pemberian ASI eksklusif dengan kecukupan gizi balita.

\section{DAFTAR PUSTAKA}

Agudelo, S. Gamboa, O. Rodriguez, F. Cala, S. Gualdron, N. Obando, E and Padron, M.L. (2016). The Effect of Skin-To-Skin Contact at Birth, Early Versus Immediate, on The Duration of Exclusive Human Lactancy in FullTerm Newborns Treated at The Clinica Universidad De La Sabana: Study Protocol for A Randomized Clinical Trial. Biomed Central (2016) 17:251

https://www.ncbi.nlm.nih.gov/pubmed 127782829 diakses 10 Desember 2016.

Dinkes DIY. 2016. Profil Kesehatan Daerah Istimewa Yogyakarta Tahun 2015. DIY: Dinas Kesehatan Daerah Istimewa Yogyakarta.

Fikawati dan Syafiq. (2009). Penyebab Keberhasilan dan Kegagalan Praktik Pemberian ASI Eksklusif. Jurnal IImu Kesehatan Masyarakat Nasional Vol. 4

No.3

http://jurnalkesmas.ui.ac.id/kesmas/a rticle/view/184/184 diakses 5 Desember 2016.

Agunbiade O, M. Ogunleye, O, V. Constraints to Exclusive Breastfeeding Practice among Breastfeeding Mothers in Southwest Nigeria. Implications for Scaling 
Astrida Budiarti. Penyebab Keberhasilan Dan Kegagalan Pemberian Asi Eksklusif Di Puskesmas Jagir Surabaya

Up:International Breastfeeding Journal 2012. 2(7), pp.1-10.
Kecerdasan dan Kelincahan Sikecil. Edisi 1. Yogyakarta.

Arisman. Gizi Dalam Daur Kehidupan. Jakarta: Penerbit Buku Kedokteran EGC, 2010.

Departemen Kesehatan Republik Indonesia. 2013. Pedoman Pelayanan Anak Gizi Buruk. http://gizi.depkes.go.id/wp. Diakses 09/03/2014.

Depkes RI (2008). Penurunan Angka Kematian Ibu Dan Bayi Jadi Program Prioritas, http://www.depkes.go.id diperoleh tanggal 24 Desember 2009.

Depkes RI. 2008. Keputusan Menteri Kesehatan Republik Indonesia Nomor 450/MENKES/IV/Tentang pemberian ASI Eksklusif pada Bayi Indonesia, Manajemen Laktasi. Jakarta, 2005.

Depkes. 2007. Kebijakan Departemen Kesehatan Tentang Peningkatan Pemberian ASI Pekerja Wanita.

Kemenkes RI, 2010. IImu Kesehatan Anak. Jakarta: Penerbit Rineka Cipta.

Kristiyansari, W. 2009. ASI, Menyusui dan Sadari. Yogjakarta: Nuha Medika.

Riskesdas Riset Kesehatan Dasar. 2010. Riset Badan Litbangkes [internet]. [Di unduh Pada 2015 Januari 29] Tersedia pada: http://labdata.litbang.depkes.go.Id/ris etbadanlitbangkes/menuriskesnas/m enu-riskesdas/374-rkd-2013 diakses 31 Maret 2014.

Roesli. U. (2012). Panduan Inisiasi Menyusui Dini Plus ASI Eksklusif. Jakarta: Pustaka Bunda.

Yuliarti, N. 2010. Keajaiban ASI Makanan Terbaik Untuk Kesehatan, 